\title{
Effect-site concentration of remifentanil for preventing propofol injection pain during induction of balanced anesthesia
}

Received August 21, 2019

Revised September 26, 2019

Accepted September 27, 2019

\section{Corresponding author}

Hyung Gong Lee, M.D.

Department of Anesthesiology and

Pain Medicine, Chonnam National

University Hospital, Chonnam National

University Medical School, 42 Jebong-

ro, Dong-gu, Gwangju 61469, Korea

Tel: 82-62-220-6893

Fax: 82-62-232-6294

E-mail: leehg@chonnam.ac.kr

\section{Joungmin Kim ${ }^{1,2}$, Daehoon Kim², and Hyung Gong Lee ${ }^{1,2}$}

Department of Anesthesiology and Pain Medicine, ${ }^{1}$ Chonnam National University Medical School, ${ }^{2}$ Chonnam National University Hospital, Gwangju, Korea

\begin{abstract}
Background: Despite various strategies designed for preventing pain from propofol injection, it is still common and distressing to the patients. The purpose of the present study was to investigate the adequate effect-site concentration $(\mathrm{Ce})$ of remifentanil to prevent pain due to propofol injection.
\end{abstract}

Methods: A total of 160 adults scheduled for elective surgery were randomly assigned to one of four groups receiving normal saline (group S) or remifentanil at a Ce of 2 (group R2), 3 (group R3), or $4 \mathrm{ng} / \mathrm{ml}$ (group R4), administered via target-controlled infusion, followed by the injection of $2 \mathrm{mg} / \mathrm{kg}$ of propofol (delivered with 1\% lipid propofol). The severity and incidence of injection pain were assessed on a four-point scale.

Results: The incidence of propofol injection pain was significantly lower in group R2, R3, or R4 than in group S (30\%, $5 \%$, or $2.5 \%$ vs. $70 \%$, respectively). Moreover, the intensity of the pain was lesser in group R2, R3, or R4 than in group S. However, the incidence or severity of injection was not different between groups R3 and R4.

Conclusions: During the induction of balanced anesthesia using propofol injection, pretreatment with remifentanil at a target Ce of $3 \mathrm{ng} / \mathrm{ml}$ effectively reduced propofol injection pain in adults.

Keywords: Injection; Pain; Propofol; Remifentanil; Target-controlled infusion.

\section{INTRODUCTION}

Propofol is widely used as the induction agent of anesthesia owing to its pharmacological advantages, including rapid onset time, short duration of action, easy titration, and a favorable side-effect profile [1]. Recently, its use has gradually expanded to sedation for outpatient procedures [2,3].

Despite these advantages, pain during vascular injection is a major drawback of propofol use. Without other treatments, pain is experienced after propofol injection by approximately $70 \%$ of the patients [4]. A few patients complained that the propofol injection site was the most pain- ful site throughout the perioperative period.

Therefore, numerous techniques have been use to reduce propofol injection pain. In a recent systematic review, Jalota et al. [5] recommended the routine use of opioids in all patients before propofol injection for general anesthesia, unless contraindicated. There have been several studies on the preventive effect of remifentanil on pain from a single injection or continuous infusion of propofol in adults [6-8]. Compared to other opioids, remifentanil has faster onset, shorter duration of action, and shorter context-sensitive half-life [9].

Lee et al. [10] showed that effect-site concentrations (Ce)

This is an Open Access article distributed under the terms of the Creative Commons Attribution Non-Commercial License (http://creativecommons.org/licenses/by-nc/4.0) which permits unrestricted non-commercial use, distribution, and reproduction in any medium, provided the original work is properly cited.

Copyright (C) the Korean Society of Anesthesiologists, 2020 
of remifentanil of 4 and $6 \mathrm{ng} / \mathrm{ml}$ reduced the injection pain from $2 \%$ propofol infusions during the induction of anesthesia with target-controlled infusion (TCI). The $2 \%$ propofol solution is commonly used for the induction of total intravenous anesthesia (TIVA), but the $1 \%$ propofol solution is usually used for the induction of balanced anesthesia. As the $2 \%$ propofol solution elicits more intense pain than the $1 \%$ propofol solution, Ce of remifentanil required to prevent propofol injection pain may be different.

The aim of this study was to determine the effective Ce of remifentanil to reduce pain from the injection of $1 \%$ propofol, which is used to induce anesthesia in adults.

\section{MATERIALS AND METHODS}

This study was approved by the Institutional Review Board (2015-2019) (IRB No: CNUHH-2015-019), and written informed consent was obtained from all study participants. We prospectively performed this study on a total of 160 patients, aged 20-65 years (American Society of Anesthesiologists physical status I or II), undergoing elective surgery under general anesthesia. The exclusion criteria were: (1) known allergies to opioids and propofol, (2) neurological deficits or psychiatric disorders, (3) current use of pain medication or sedatives, and (4) a history of drug abuse.

Using a computer-generated randomization table, each patient was randomly allocated to group S, R2, R3, or R4 (each $\mathrm{n}=40$ ) and administered with normal saline or remifentanil at a Ce of 2, 3, or $4 \mathrm{ng} / \mathrm{ml}$, respectively (Fig. 1). Remifentanil 1 mg (Ultiva ${ }^{\circledR}$, GlaxoSmithKline, Belgium) was diluted with $20 \mathrm{ml}$ of normal saline. Normal saline was delivered with a 20-ml syringe to controls. All study drugs

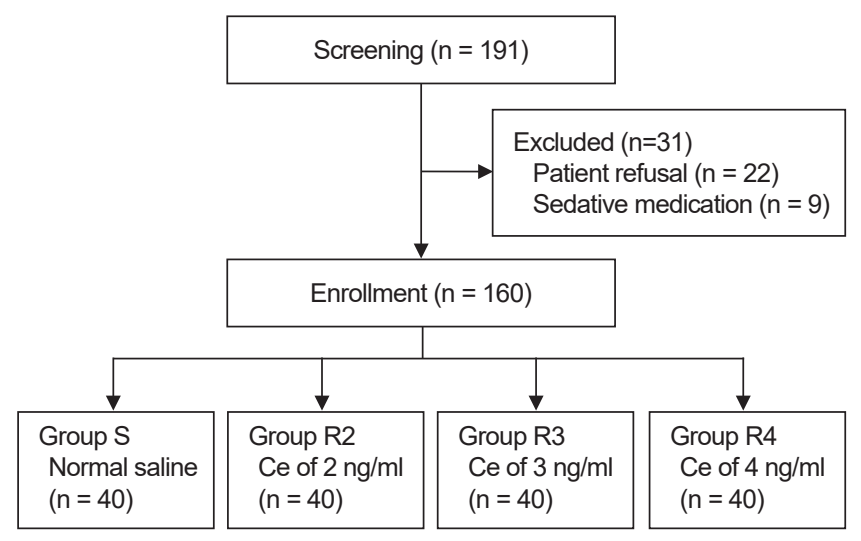

Fig. 1. CONSORT flow diagram of participants through the study. Ce: effect-site concentration. were administered using a Minto pharmacokinetic model [11] in a TCI device (Orchestra, Fresenius-Vial, France). The infusion pump was covered to blind the patients, anesthesiologists, and investigators.

The patients were not medicated before the surgery, and a 20-gauge venous cannula was placed in their cephalic vein. Standard monitoring and assessment were performed continuously, which included electrocardiography, pulse oximetry, and non-invasive monitoring of arterial pressure. When the predetermined target Ce of remifentanil was achieved, propofol $2 \mathrm{mg} / \mathrm{kg}$ (1\% Anepol ${ }^{\circledR}$, Hana Pharm. Co., Ltd., Korea) was administered intravenously over $30 \mathrm{~s}$. During the propofol injection, the pain severity was assessed using the following four-point scale: 1 (no pain), no verbal/facial/motor reaction to the injection; 2 (mild pain), a minor verbal/facial/motor reaction to the injection; 3 (moderate pain), the patient complained of pain, but there was no accompanied grimacing or withdrawal; 4 (severe pain), the patient complained of pain, and there was facial grimacing or withdrawal of the arm [12]. After the patients were unconscious, tracheal intubation was performed following an injection of $0.8 \mathrm{mg} / \mathrm{kg}$ of rocuronium, and balanced anesthesia was maintained with sevoflurane and continuous remifentanil infusion via the TCI pump. Heart rates (HRs) and mean arterial pressures (MAPs) were compared before the infusion and after the remifentanil target Ce was reached. Remifentanil-related hypotension ( $>20 \%$ decrease in MAP) and bradycardia ( $\mathrm{HR}<45$ beats $/ \mathrm{min}$ ) were assessed. Chest wall rigidity, desaturation, and minor complications, such as dizziness and cough, were also assessed. The patients were assessed for 24 postoperative hours for adverse effects, such as pain, edema, and flare response at the propofol injection site.

Based on previous studies [4], the sample size of $160 \mathrm{sub-}$ jects in four groups (with an assumed dropout rate of 5\%) was calculated to have a power of $85 \%$ to detect a linearly decreasing trend using a one-sided z-test with continuity correction, with a significance level of at least 0.05 (PASS 13.0.05, NCSS, LCC, USA). All statistical analyses were performed with the SPSS software, version 15.0 (SPSS Inc., USA). The one-way analysis of variance test was used for normally distributed continuous variables (e.g., age, height, and weight), and the chi-squared test was used for discrete variables (e.g., sex). Fisher's exact test and the KruskalWallis rank test were used to detect any differences in the incidence of propofol injection pain and mean pain intensity among groups, respectively. $\mathrm{P}$ values less than 0.05 
were considered statistically significant. Results are expressed as mean \pm SD or absolute numbers (\%).

\section{RESULTS}

The study enrolled 160 people, none of whom dropped out. There were no differences in demographic characters, such as age, gender, weight, or height, among the groups (Table 1).

The incidence of propofol-induced pain was significantly lower in groups R2, R3, and R4 (30\%, 5\%, and 2.5\%, respectively) than in group S ( $70 \%, \mathrm{P}<0.05$, Table 2$)$. In addition, the severity of propofol-induced pain was significantly lower in groups R2, R3, and R4 compared to group $\mathrm{S}(\mathrm{P}<0.05$, Table 2$)$. However, there were no significant differences in pain incidence or severity between groups R3 and R4.

Although the changes in HR and MAP after remifentanil or saline infusion were significant in all groups compared to baseline, reductions in HR and MAP were of no clinical importance, and no patients required treatment for hypotension or bradycardia (Table 3). Participants did not experience major adverse events, such as desaturation or chest wall rigidity during the study period (Table 4). Minor complications, including dizziness and cough, occurred more frequently in groups R2, R3, and R4 than in group $\mathrm{S}(\mathrm{P}<$ 0.05). However, the incidence of complications did not differ significantly among the three groups receiving remifentanil (Table 4). No side effects at the injection site were seen in any patient.

\section{DISCUSSION}

This study showed that the administration of remifentanil at target Ce of 2, 3, or $4 \mathrm{ng} / \mathrm{ml}$ significantly reduced the

Table 1. Demographic Characteristic

\begin{tabular}{lcccc}
\hline & Group S $(\mathrm{n}=40)$ & Group R2 $(\mathrm{n}=40)$ & Group R3 $(\mathrm{n}=40)$ & Group R4 $(\mathrm{n}=40)$ \\
\hline Target Ce of remifentanil $(\mathrm{ng} / \mathrm{ml})$ & 0 & 2 & 3 & 4 \\
Sex $(\mathrm{M} / \mathrm{F})$ & $15 / 25$ & $15 / 25$ & $14 / 26$ & $15 / 25$ \\
Age $(\mathrm{yr})$ & $49.0 \pm 9.5$ & $48.0 \pm 7.7$ & $50.0 \pm 9.3$ & $48.0 \pm 9.6$ \\
Weight $(\mathrm{kg})$ & $63.6 \pm 10.7$ & $62.6 \pm 9.2$ & $63.5 \pm 11.6$ & $65.1 \pm 11.0$ \\
Height $(\mathrm{cm})$ & $159.9 \pm 10.2$ & $164.0 \pm 6.5$ & $162.2 \pm 9.0$ & $161.7 \pm 10.0$ \\
\hline
\end{tabular}

Values are presented as number of patients or mean \pm SD. There were no significant differences among the four groups. Ce: effect-site concentration.

Table 2. Incidence and Severity of Pain with Propofol Injection

\begin{tabular}{|c|c|c|c|c|}
\hline & Group S $(n=40)$ & Group R2* $(n=40)$ & Group R3 ${ }^{*, \dagger}(n=40)$ & Group R4 ${ }^{*, \dagger}(n=40)$ \\
\hline Incidence of pain & 28 & 12 & 2 & 1 \\
\hline \multicolumn{5}{|l|}{ Severity of pain } \\
\hline 1 (no pain) & 12 & 28 & 38 & 39 \\
\hline 2 (mild pain) & 16 & 12 & 2 & 1 \\
\hline 3 (moderate pain) & 11 & 0 & 0 & 0 \\
\hline 4 (severe pain) & 1 & 0 & 0 & 0 \\
\hline
\end{tabular}

Values are presented as number of patients (\%). $* \mathrm{P}<0.05$ for comparison of the incidence and severity of pain with the control. ${ }^{\dagger} \mathrm{P}<0.05$ for comparison of the incidence and severity of pain with Group R2. However, there was no significant difference in the incidence or severity of pain between groups R3 and R4.

Table 3. Hemodynamic Changes During the Induction of General Anesthesia

\begin{tabular}{lccccc}
\hline & \multicolumn{2}{c}{ Heart rate } & & \multicolumn{2}{c}{ Mean arterial pressure } \\
\cline { 2 - 3 } \cline { 5 - 6 } & Baseline & Before intubation & & Baseline & Before intubation \\
\hline Group S $(n=40)$ & $78.4 \pm 9.7$ & $68.6 \pm 8.9^{*}$ & & $99.6 \pm 10.3$ & $80.0 \pm 8.3^{*}$ \\
Group R2 $(n=40)$ & $75.2 \pm 11.4$ & $64.4 \pm 9.5^{*}$ & & $100.9 \pm 9.9$ & $76.4 \pm 7.3^{*}$ \\
Group R3 $(n=40)$ & $79.9 \pm 13.7$ & $65.4 \pm 10.6^{*}$ & & $101.0 \pm 10.4$ & $72.6 \pm 8.4^{*}$ \\
Group R4 $(n=40)$ & $81.5 \pm 13.6$ & $64.4 \pm 8.1^{*}$ & & $99.2 \pm 13.5$ & $70.6 \pm 9.2^{*}$ \\
\hline
\end{tabular}

Values are presented as mean \pm SD. Although changes in the heart rate (HR) and mean arterial pressure (MAP) after remifentanil or saline infusion were significant compare to baseline $\left({ }^{*} \mathrm{P}<0.05\right)$ in all groups, reductions in HR or MAP were of no clinical importance, and no patients required treatment for hypotension or bradycardia. 
Table 4. Incidence of Complications in Patients Who Received Normal Saline (Group S) or Remifentanil at Target Effect-site Concentrations of 2 , 3 , or $4 \mathrm{ng} / \mathrm{ml}$

\begin{tabular}{lcccc}
\hline & Group S $(n=40)$ & Group R2 $(n=40)$ & Group R3 $(n=40)$ & Group R4 $(n=40)$ \\
\hline Desaturation & 0 & 0 & 0 & 0 \\
Chest wall rigidity & 0 & 0 & 0 & 0 \\
Cough & 0 & 0 & 1 & 2 \\
Dizziness & 0 & $17 *$ & $18^{*}$ & $20 *$ \\
\hline
\end{tabular}

Values are presented as number of patients. There were no significant differences in the incidence of desaturation or chest wall rigidity among the groups. Dizziness was significantly more frequent in groups R2, R3, and R4 (*P $<0.05)$ compared to the control group, although the incidence of complications was not significantly different among the three study groups.

incidence and severity of propofol injection pain during the induction of balanced anesthesia in adults. There were no differences between target Ce of 3 and $4 \mathrm{ng} / \mathrm{ml}$.

During the induction of anesthesia, the propofol injection often causes pain, which might be distressing to the patients. In the present study, propofol injection pain occurred in $26(70 \%)$ patients in group S, which was the saline-only control group, consistent with previous reports [4]. Although the mechanism underlying propofol injection pain has not been fully understood, initial and delayed pain seem to be involved with the immediate stimulation of nociceptors and activation of pain mediators, respectively $[13,14]$.

As opioids, including remifentanil, are commonly used for balanced anesthesia, the use of opioids for induction seems reasonable because opioids have half the risk of propofol injection pain [5]. Moreover, previous studies showed that pretreatment with remifentanil reduced the incidence and severity of propofol injection pain with varying results [6-8]. A previous study reported that pretreatment with remifentanil was effective in reducing propofol injection pain, and a dose of at least $0.02 \mathrm{mg}$ of remifentanil should be used for this purpose [6]. Another study showed that $0.25 \mu \mathrm{g} / \mathrm{kg} / \mathrm{min}$ of remifentanil started $1 \mathrm{~min}$ earlier was more effective than that administered immediately before propofol injection [8]. Therefore, previous data indicate that both dose and time intervals are fundamental factors for the maximal effect of remifentanil on propofol injection pain [10]. TCI of remifentanil is suitable for use as a part of an anesthesia regimen owing to its pharmacologic advantages, which include rapid onset. This pharmacologic property allows the desired targeted blood plasma concentration of remifentanil to be quickly achieved. Therefore, pretreatment with remifentanil at an efficacious target Ce could be a good method to prevent propofol injection pain for the induction of balanced anesthesia.

In adult women, the effective concentrations of remifen- tanil to cause inhibitions by $50 \%\left(\mathrm{EC}_{50}\right)$ and $95 \%$ for minimizing propofol infusion pain during the induction of TIVA were 3.09 and $3.78 \mathrm{ng} / \mathrm{ml}$, respectively [15]. Lee et al. [10] reported that pretreatment with remifentanil at a target $\mathrm{Ce}$ of $4 \mathrm{ng} / \mathrm{ml}$ effectively reduced the frequency and intensity of pain from propofol infusions during the induction of TIVA, without significant complications.

The $2 \%$ propofol solution, containing more aqueous propofol, might cause more infusion pain than the $1 \%$ propofol solution [10]. In this study, we used the $1 \%$ propofol solution as it is commonly used for the induction of balanced anesthesia. As the $2 \%$ propofol solution elicits more intense pain than the $1 \%$ propofol solution, in this study, the test doses of target Ce of remifentanil were lower than $4 \mathrm{ng} / \mathrm{ml}$.

In this study, the incidence of propofol injection pain in group R2, R3, or R4 (30\%, 5\%, and 2.5\%, respectively) was significantly lower than that in the control group (70\%). The severity of propofol injection pain was also significantly lower in group R2, R3, or R4 than in the control group. No moderate-to-severe pain was reported in group R2, R3, or R4 $(0 \%)$ whereas it was experienced by $30 \%$ of the patients in the control group. The incidence or severity of pain was not significantly different between groups R3 and $\mathrm{R} 4$, and the occurrence of complications was not significantly different between groups R3 and R4. This finding suggests that remifentanil at a Ce of $3 \mathrm{ng} / \mathrm{ml}$ might be the optimal concentration to reduce propofol injection pain for the induction of balanced anesthesia in adults. The pain-relieving effect of remifentanil might be mediated through central opioid receptors because a tourniquet technique was not used for the injection of remifentanil, and propofol was injected when the target Ce of remifentanil was reached.

Previous studies examining remifentanil at $\mathrm{EC}_{50}$ to prevent hemodynamic changes following endotracheal intubation showed that remifentanil at Ce of $2.0-5.0 \mathrm{ng} / \mathrm{ml}$ did not cause significant hypotension, bradycardia, or chest 
tightness [16]. Although in the present study, reductions in HR and MAP following the administration of remifentanil were significant, no adult patients with American Society of Anesthesiologists physical status I or II required treatment for hypotension or bradycardia, consistent with previous reports $[10,16]$.

This study had two limitations, and the findings of this study should be considered within the context of these limitations.

First, the study population was limited to relatively young patients. As older patients are more sensitive to opioids, age-related variations in the effects should be considered. Second, the prevalence of propofol injection pain could be influenced by the patient's sex. Remifentanil at $\mathrm{EC}_{50}$ used to reduce propofol injection pain was lower in women than in men [15].

In conclusion, we showed that remifentanil infusion at a target Ce of $3 \mathrm{ng} / \mathrm{ml}$ for the induction of balanced anesthesia using a single propofol injection was a useful strategy to minimize propofol injection pain in adults, without causing significant complications.

\section{CONFLICTS OF INTEREST}

No potential conflict of interest relevant to this article was reported.

\section{AUTHOR CONTRIBUTIONS}

Conceptualization: Joungmin Kim, Hyung Gon Lee. Data acquisition: Hyung Gon Lee. Formal analysis: Hyung Gon Lee, Daehoon Kim. Supervision: Hyung Gon Lee. Writingoriginal draft: Joungmin Kim, Daehoon Kim. Writing-review \& editing: Joungmin Kim, Hyung Gon Lee.

\section{ORCID}

Joungmin Kim, https://orcid.org/0000-0003-1135-1968

Daehoon Kim, https://orcid.org/0000-0001-6275-2433

Hyung Gong Lee, https://orcid.org/0000-0003-4898-4355

\section{REFERENCES}

1. Marik PE. Propofol: therapeutic indications and side-effects. Curr Pharm Des 2004; 10: 3639-49.

2. Angelini G, Ketzler JT, Coursin DB. Use of propofol and other nonbenzodiazepine sedatives in the intensive care unit. Crit Care Clin 2001; 17: 863-80.

3. Külling D, Rothenbühler R, Inauen W. Safety of nonanesthetist sedation with propofol for outpatient colonoscopy and esophagogastroduodenoscopy. Endoscopy 2003; 35: 679-82.

4. Picard P, Tramèr MR. Prevention of pain on injection with propofol: a quantitative systematic review. Anesth Analg 2000; 90: 963-9.

5. Jalota L, Kalira V, George E, Shi YY, Hornuss C, Radke O, et al. Prevention of pain on injection of propofol: systematic review and meta-analysis. BMJ 2011; 342: d1110.

6. Iyilikci L, Balkan BK, Gökel E, Günerli A, Ellidokuz H. The effects of alfentanil or remifentanil pretreatment on propofol injection pain. J Clin Anesth 2004; 16: 499-502.

7. Roehm KD, Piper SN, Maleck WH, Boldt J. Prevention of propofol-induced injection pain by remifentanil: a placebo-controlled comparison with lidocaine. Anaesthesia 2003; 58: 165 70.

8. Basaranoglu G, Erden V, Delatioglu H, Saitoglu L. Reduction of pain on injection of propofol using meperidine and remifentanil. Eur J Anaesthesiol 2005; 22: 890-2.

9. Egan TD, Kern SE, Muir KT, White J. Remifentanil by bolus injection: a safety, pharmacokinetic, pharmacodynamic, and age effect investigation in human volunteers. Br J Anaesth 2004; 92: $335-43$

10. Lee JR, Jung CW, Lee YH. Reduction of pain during induction with target-controlled propofol and remifentanil. Br J Anaesth 2007; 99: 876-80.

11. Minto CF, Schnider TW, Egan TD, Youngs E, Lemmens HJ, Gambus PL, et al. Influence of age and gender on the pharmacokinetics and pharmacodynamics of remifentanil. I. Model development. Anesthesiology 1997; 86: 10-23.

12. King SY, Davis FM, Wells JE, Murchison DJ, Pryor PJ. Lidocaine for the prevention of pain due to injection of propofol. Anesth Analg 1992; 74: 246-9.

13. Briggs LP, Clarke RS, Dundee JW, Moore J, Bahar M, Wright PJ. Use of di-isopropyl phenol as main agent for short procedures. Br J Anaesth 1981; 53: 1197-202.

14. Scott RP, Saunders DA, Norman J. Propofol: clinical strategies for preventing the pain of injection. Anaesthesia 1988; 43: 492-4.

15. Lee JY, Yang H, Choi SH, Shin DW, Hong SK, Chun DH. The optimal effect-site concentration of remifentanil to attenuate the pain caused by propofol. Korean J Anesthesiol 2012; 63: 108-12.

16. Yon JH, Jo JK, Kwon YS, Park HG, Lee S. Effect-site concentration of remifentanil for blunting hemodynamic responses to tracheal intubation using light wand during target controlled infusion-total intravenous anesthesia. Korean J Anesthesiol 2011; 60: 398-402. 